\title{
Hipertensión portal izquierda con sangrado por varices gástricas como forma de presentación de un hipernefroma
}

\author{
M. D. JOYA SEIJO, P. DEL VALLE LOARTE, J. MARCO MARTÍNEZ, N. HERRERA \\ MERINO $^{1}$, J. L. AGUD APARICIO \\ Servicios de Medicina Interna y ${ }^{\prime}$ Cirugía General. Hospital Severo Ochoa. Leganés, Madrid \\ SINISTRAL PORTAL HYPERTENSION WITH BLEEDING GASTRIC \\ VARICES AS INITIAL MANIFESTATION OF RENAL-CELL CARCINOMA
}

\section{RESUMEN}

Describimos un caso clínico en el que la manifestación inicial de un hipernefroma fue un sangrado digestivo alto, secundario a una hipertensión portal siniestra o izquierda.

La hipertensión portal izquierda es un síndrome clínico que consiste en la trombosis de la vena esplénica, que se manifiesta por un sangrado por varices gástricas aisladas, con una vena porta permeable y una función hepática normal. La causa más frecuente de este síndrome es la patología pancreática.

El hipernefroma se caracteriza por su diversidad de manifestaciones clínicas motivo por el cual se ha llamado el tumor del internista. En este caso clínico la paciente presenta un sangrado masivo por varices gástricas secundarias a la trombosis de la esplénica por una masa retroperitoneal. Se realizó un TAC abdominal en el que se apreció dicha masa, siendo compatible con un hipernefroma que infiltraba la cola del páncreas y producía una trombosis de la vena esplénica. La paciente fue operada con resección completa del tumor y esplenectomía no volviendo a presentar sangrado digestivo.

PALABRAS CLAVE: Hipertensión portal. Hipernefroma. Varices gástricas. Vena esplénica. Esplenectomía.

\begin{abstract}
We report a clinic case of Renal-cell carcinoma presenting as sinistral portal hypertension; a clinical syndrome consisting of esplenic vein thrombosis manifested as isolated gastric varices with patent portal vein and normal hepatic function. The most frecuent cause of this syndrome is pancreatic pathology.

Renal-cell carcinoma is characterized by a wide variety of symptoms as initial manifestation. In our case, the patient developed a massive gastrointestinal bleeding secondary to isolated gastric varices caused by splenic vein thrombosis due to extrinsic compression by a hypernephroma that infiltrated the pancreas.
\end{abstract}

KEY WORDS: Portal hipertensión. Renal-cell carcinoma. Gastric varices. Splenic vein. Esplenectomy.

Joya Seijo MD, del Valle Loarte P, Marco Martínez J, Herrera Merino N, Agud Aparicio JL. Hipertensión portal izquierda con sangrado por varices gástricas como forma de presentación de un hipernefroma. An Med Interna (Madrid) 2004; 21: 283-284.

\section{INTRODUCCIÓN}

La hipertensión portal izquierda es un síndrome clínico causado por la obstrucción, en la mayor parte de los casos trombosis, de la vena esplénica.

La trombosis de la vena esplénica clásicamente se presenta con la triada de varices gástricas aisladas, esplenomegalia y función hepática normal. La etiología más frecuente de este síndrome clínico es la patología pancreática; ya sea pancreatitis aguda o crónica, cáncer pancreático o pseudoquiste, aunque puede haber otras causas incluidas traumatismo, tuberculosis, fibrosis retroperitoneal, úlcera péptica e hipercoagulabilidad (Tabla I).

Una revisión de la literatura inglesa recoge 209 casos de obstrucción de la vena esplénica. La causa más frecuente era la pancreatitis con el $65 \%$ de los casos, seguida por la neoplasia pancreática con el 18\% (1).

El cáncer de páncreas puede causar trombosis por invasión directa, compresión extrínseca por efecto masa o por favorecer un estado de hipercoagulabilidad.

\section{TABLA I}

\section{CAUSAS DE HIPERTENSIÓN PORTAL IZQUIERDA}

\author{
Neoplasia pancreática \\ Pancreatitis crónica \\ Pseudoquiste pancreático \\ Traumatismo \\ Tuberculosis \\ Fibrosis retroperitoneal \\ Ulcera péptica \\ Hipercoagulailidad \\ Otras
}

Esto no es sorprendente porque la vena esplénica avanza en íntimo contacto con el páncreas a lo largo de todo su recorrido. Cualquier inflamación, dejando a un lado el proceso maligno, puede afectar a la vena esplénica.

La trombosis de la vena esplénica normalmente se presenta 
con varices gástricas aisladas como resultado del hiperaflujo hacia la vena gástrica izquierda por las venas gástricas cortas o el sistema venoso epiploico. Sin embargo, puede aparecer sin varices gástricas e incluso con varices esofágicas. Esto se debe al irregular lugar de drenaje de la vena gástrica izquierda. Cuando drena en la vena esplénica, impide la descompresión por esta ruta venosa y aumenta el flujo en el sistema de la ácigos por las venas esofágicas produciendo varices esofágicas, pero no gástricas. Independientemente de la localización de las varices, la función hepática es normal (2).

Aproximadamente entre el 72 y el 50\% de los casos, según las series, es el sangrado de las varices el motivo del inicio del estudio clínico (3).

El gold estándar del diagnóstico de la trombosis de la porta es la arteriografía.

La esplenectomía es el tratamiento de elección para el sangrado por varices gástricas aisladas con función hepática normal. En el estudio de Evans y cols., de doce pacientes con hipertensión portal siniestra, se realizó esplenectomía a diez de ellos resangrando sólo uno en un seguimiento de hasta 14 años (4).

\section{CASO APORTADO}

Paciente de 46 años de edad, obesa, en estudio, por su médico de Atención Primaria, por anemia ferropénica, en tratamiento con hierro. El día que ingresa presenta dos vómitos hemáticos sin inestabilidad hemodinámica. La exploración física no presentaba alteraciones. Los estudios de laboratorio fueron normales excepto hematocrito de $21,7 \%$ y hemoglobina de $6,7 \mathrm{~g} / \mathrm{dl}$. En la gastroscopia realizada en urgencias se objetiva hemorragia digestiva alta activa en región subcardial probablemente por úlcera, no se ve claramente la lesión, que se esclerosa. Se transfunden dos concentrados de hematíes sin volver a presentar datos de sangrado siendo dada de alta, tras una endoscopia de control normal, con el diagnóstico de probable síndrome de Dielafou.

A los 3 meses reingresa por anemia severa $\mathrm{Hb} 5,2 \mathrm{~g} / \mathrm{dl}$ pese a tratamiento con hierro. Se realiza gastroscopia objetivándose, de nuevo, hemorragia activa a nivel subcardial que se esclerosa. La paciente a los 5 días presenta varios episodios de hemorragia digestiva alta autolimitada que requieren la transfusión en total de 10 concentrados de hematíes, se realiza endoscopia sin objetivar punto de sangrado. Tras un nuevo episodio de hematemesis intensa, es intervenida de forma urgente, apreciándose masa retroperitoneal que origina hipertensión portal segmentaria con varices fúndicas. Se realiza gastrotomía y sutura de varices controlándose la hemorragia. Se decide completar el estudio para evaluar la masa retroperitoneal, para lo que se solicita un TAC Abdominal en el que se evidencia, masa retroperitoneal sugestiva de hipernefroma, trombosis de la vena esplénica, colaterales gástricas y esplenomegalia (Fig. 1).

Es reintervenida, realizándose nefrectomia radical con linfadenectomia de vena y arteria renal junto con pancreatectomia córporo-caudal, esplenectomía, resección en bloque de grasa perirrenal y linfadenectomía paraórtica izquierda y de tronco celiaco. La anatomía

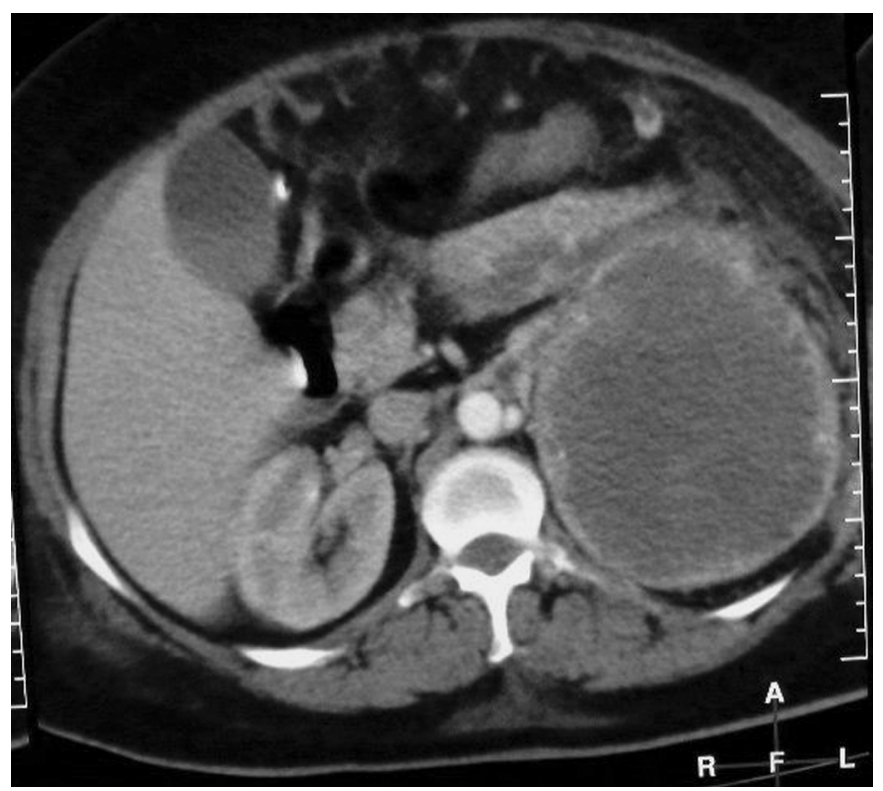

Fig. 1.

patológica dio el diagnóstico de carcinoma de células claras que infiltra la grasa perirrenal y la cola del páncreas. Bazo y ganglios linfáticos libres de infiltración. No ha vuelto a presentar sangrado.

\section{DISCUSIÓN}

Las varices gástricas aisladas son la manifestación clínica, si la función hepática es normal, de una hipertensión portal izquierda (5).

Aunque las enfermedades asociadas más frecuentemente descritas han sido la pancreatitis y el cáncer de páncreas, múltiples entidades se han comunicado de forma esporádica (6).

En nuestra revisión no hemos encontrado ningún caso de hipernefroma asociado a esta entidad.

El crecimiento insidioso del hipernefroma y su escasez de sintomas provoca en muchas ocasiones su diagnóstico en un estadio avanzado (7). En esta ocasión el crecimiento del tumor ha sido asintomático hasta causar infiltración de la cola del páncreas, trombosis de la vena esplénica y posteriormente sangrado por varices gástricas aisladas.

El gold estándar del diagnóstico de hipertensión portal izquierda es la arteriografía aunque el TAC abdominal es la herramienta más útil en la practica clínica pues a la vez que confirma el diagnóstico puede darnos la etiología.

La esplenectomía es un tratamiento eficaz, con un índice de recidiva muy bajo. El pronóstico, por tanto, viene dado por la enfermedad subyacente.

\section{Bibliografía}

1. Olakowski M, Lampe P, Boldys H, Slota J, Olakowska F. Neuroendocrine pancreatic carcinoma causing sinistral portal hypertension.Med Sci Monit 2001; 7: 1326-8

2. Chang CY. Pancreatic Adenocarcinoma presenting as siniestral portal hypertension: an unusal presentation of pancreatic cancer. Yale J Biol Med 1999; 72: 295-300.

3. Zadrozny D. Left -side portal hypertension as a clinical problem. WIAD Lek 1999; 52: 494-9

4. Evans G, Yellin A, Weaver F, Stain S. Sinistral (left side) portal hyper- tension. Am Surg 1970; 56: 758-63.

5. Nagral S, Shah S, Gandhi M, Mathur SK.Bleeding isolated gastric varices: a retrospective analysis. Indian J Gastrenterol 1999; 18: 6972

6. Seenu V,Goel AK,Shukla NK, Dawar R, Sood S. Hodgkin's lynphoma of colon:an unusual cause of isolated splenic vein obstruction. Indian J Gastroenterol 1994; 13: 70-1

7. Motzer RJ, Bander NH, Nanus MD. Renal-Cell Carcimoma. N Engl J Med 1996; 335: 865-875. 